\title{
A STUDY OF VARIOUS DIGITAL MARKETING TRENDS USED BY VARIOUS BUSINESSES DURING THE PANDEMIC
}

\author{
${ }^{*}$ Sanjeevani Pandey, ${ }^{2}$ Dr Pranati Tilak \\ ${ }^{1}$ Assistant Professor, PIBM - Chinchwad, Pune \\ ${ }^{2}$ Dean, Department of Management Studies, TMV, Pune
}

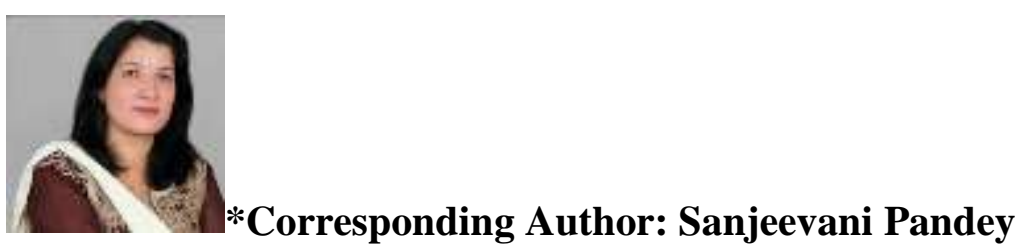

Article DOI: https://doi.org/10.36713/epra7905

DOI No: 10.36713/epra7905

\begin{abstract}
The unprecedented event of the COVID-19 pandemic severely hit every stratum of the economy. Right from local business \& start-ups to multinational chains, every enterprise experienced a sag because of a sudden \& massive hindrance to their networking \& reachability to clientele. Amidst this strenuous financial environment, some budding trends accelerated to become core competencies \& survival strategies of these businesses. Digital Marketing \& leveraging a presence over the internet expedited as a life-saving, more so, a transformational strategy for many brands.

Through this study, the researcher aims to unveil the various approaches, investment trends, \& sought-after domains of digital marketing that helped brands survive the pandemic. To effectively do so, the researcher approached various digital marketing firms as sources of garnering preliminary information.

For this purpose, the researcher, with the help of primary data \& secondary data from the digital marketers, concluded that brands invested in digital marketing during the COVID-19 Pandemic, more than ever. There were also emergence of newer startup ventures \& solopreneurs who leveraged the digital media to generate profitable alternate sources of income. The most sought after digital marketing services were, Social Media Marketing(SMM), Website Development \& Search Engine Marketing (SEM).
\end{abstract}

\section{INTRODUCTION}

Digital Marketing is a new-age component of marketing that entails the use of digital technology \& infrastructure to market the products \& services of a business enterprise. It refers to advertising the goods \& services through digital channels such as messenger services, social media, search engines, websites, emails etc. in order to attain better audience reach, enhanced networking, better customer interaction \& engagement. It is more effective in comparison to other conventional marketing techniques as it entails a greater strategic approach, is cost-effective, has better ROI (Returns On Investment) \& has monitored analytics to improve the performance of every forthcoming marketing campaign. In the modern world that is bound together by the threads of digital technologies \& IT, having a credible digital presence is not just a choice but a competence for any business. Effectual digital marketing is a bullseye strategy to sustain the cut-throat competition in the markets. 
The birth of digital marketing in India traces back to the late 90s when the internet services were launched in our country \& there were merely 15000 internet users back in the day. Gradually people started using emails as means of both personal \& professional communication, \& the search engines started fetching traffic. It was after 2005 when people gained knowledge about the concept of SEO (Search Engine Optimisation) \& were inquisitive about the working of Google Algorithms. Around these years, the Social Networking Platforms had gained momentum but on personal fronts, where people used to connect with their friends and families. Steadily, these trends bloomed to the benefits of brands \& businesses. People applied the Google Ranking Algorithms to get their websites eyeballed more than that of their competitors; \& started using social media to promote their products \& services in ways that could incite the interest $\&$ attention of their audience \& target audience. In these 3 decades, the spread of digital presences of businesses has grown multifold, transforming "Digital Marketing" from just a subset of marketing to a rapidly advancing industry that holds the future!

The present-day digital marketing ranges from Search Engine Marketing \& Social Media Marketing to websites, E-Commerce \& Digital Startups. With the outbreak of the coronavirus \& the 2020 pandemic, the need for digital marketing grew greater than ever! The cease of running businesses with normalcy called for innovative measures to sustain in the game. The business didn't just commence or strengthen digital marketing to morph to the new normal scenarios but in order to pitch a transformed audience through a transformed strategy. It would be absolutely no exaggeration in saying that the COVID-19 Pandemic changed the lifestyle, habits, preferences \& psyche of people completely. To keep abreast with this new audience \& to engage with them effectively, the tool of digital marketing came in very handy. According to surveys, $54 \%$ of businesses \& marketers made use of the pandemic as an opportunity \& benefitted from enhanced networking, boosted sales \& greater profit figures as a result of their efforts \& campaigns towards Social Media Marketing, Web Presence, Paid Advertising on the Internet, Influencer Collaboration, Brand Integrations, etc. As a result of this the digital marketing \& advertising sector grew by $15 \%$ in the year 2020 (amounting to ₹15,782 $\mathrm{Cr}$ ) \& is anticipated to grow by $20 \%$ in the years $2021-2022$

\section{LITERATURE REVIEW}

1. "A Critical Review of Digital Marketing", a research paper authored by Dr Madhu Bala \& co-authored by Mr Deepak Verma, was published in the International Journal of Management, IT \& Engineering Vol. 8 Issue 10 , October 2018, ISSN: 2249-0558 Impact Factor: 7.119. The paper throws light on what the future holds in the arena of Digital Marketing. The paper was based on the current happenings in the business world \& the study was based entirely on secondary data. The paper helped in comprehending the importance of digital marketing as a cost-effective \& highly powerful medium to strengthen their client base \& to attain greater profits. Available Online at:

https://www.researchgate.net/publication/328253026_A_Critical_Review_of_Digital_Marketing

2. "Digital Marketing- A Review", a research paper authored by Dr Mrs. Vaibhava Desai, Published in International Journal of Trend in Scientific Research and Development (IJTSRD) Conference Issue | March 2019. The paper sheds knowledge on the concept of digital marketing, its meaning, the various parts of digital marketing, scope of digital marketing \& its advantages to the businesses that would help the readers to garner insightful information about this budding industry.

Available Online at: https://www.researchgate.net/publication/333709419_Digital_Marketing_A_Review

\section{OBJECTIVE OF THE STUDY}

1. To understand the trends of digital marketing that are pursued by various businesses, with respect to the COVID-19 Pandemic period.

2. To give suggestions to Digital Marketing Agencies \& Freelance Digital Marketers for increasing their clientele based on this analytical study.

\section{STATEMENT OF THE PROBLEM}

With the outbreak of the COVID-19 Pandemic \& the imposition of nationwide lockdown, businesses faced difficulty in reaching their customers with normalcy. Digital Marketing could be an effectual \& feasible solution in this regard, hence the study.

\section{HYPOTHESIS}

H0-. Social Media Marketing is not among the highly preferred digital marketing services by businesses. H1- Social Media Marketing is among the highly preferred digital marketing services by businesses. 
1. Primary Data:

\section{METHOD OF DATA COLLECTION}

Primary Data will be collected through structured questionnaire with both close ended and open ended questions

2. Secondary Data:

Secondary data will be collected from books, research journals, articles, magazines, newspapers, periodicals, related articles, websites, etc.

\section{METHODODLOGY}

The proposed research article is an empirical research study which is based upon primary data collected from 46 digital marketing agencies \& Independent Freelance Digital Marketers through 60 questionnaires sent across to various agencies \& digital marketing freelancers in Pune city.

\section{TECHNIQUES \& STATISTICAL TOOLS}

The data collected $\&$ analysed by the researcher in the due course of this study being qualitative data, the percentage method would be taken to arrive at the importance of Digital Marketing for businesses amidst the Pandemic period taking 46 Digital Marketing \& Advertising Agencies \& Freelance Digital Marketers based in Pune city as $100 \%$ of the population.

1. The scope is limited to Pune city only.

\section{SCOPE \& LIMITATIONS}

2. The Study of Various Trends of Digital Marketing opted by Various Businesses to sustain during the pandemic period.

3. The sample is limited to 46 respondents.

\section{FINDINGS}

\begin{tabular}{|l|c|c|c|}
\hline \multicolumn{1}{|c}{$\begin{array}{c}\text { Trends/Subservices in Digital } \\
\text { Marketing }\end{array}$} & Highly Preferred & $\begin{array}{c}\text { Response } \\
\text { Moderately } \\
\text { Preferred }\end{array}$ & $\begin{array}{c}\text { Not Preferred by } \\
\text { the Clientele }\end{array}$ \\
\cline { 2 - 4 } & 84 & 10 & 06 \\
\hline Social Media Marketing & 67 & 8 & 25 \\
\hline $\begin{array}{l}\text { Website } \\
\text { Design/Development/Revamping }\end{array}$ & 34 & 33 & 33 \\
\hline Search Engine Optimisation & 26 & 28 & 45 \\
\hline Search Engine Marketing & 27 & 48 & 25 \\
\hline Paid Advertising for Social Media & 31 & 33 & 36 \\
\hline Video Marketing & 12 & 13 & 75 \\
\hline $\begin{array}{l}\text { Content Marketing- Blogs, Newsletters, } \\
\text { Articles Etc }\end{array}$ & 05 & 06 & 89 \\
\hline Pitch Deck/ Corporate Profile Designing & 21 & 59 & 20 \\
\hline Email Marketing & 12 & 48 & 40 \\
\hline Messenger Marketing & 04 & 06 & 90 \\
\hline Banner/Flex/Pamphlet Designing & 03 & 0 & 97 \\
\hline Outdoor Advertsising & 13 & 24 & 63 \\
\hline Mobile App Development & & & \\
\hline
\end{tabular}




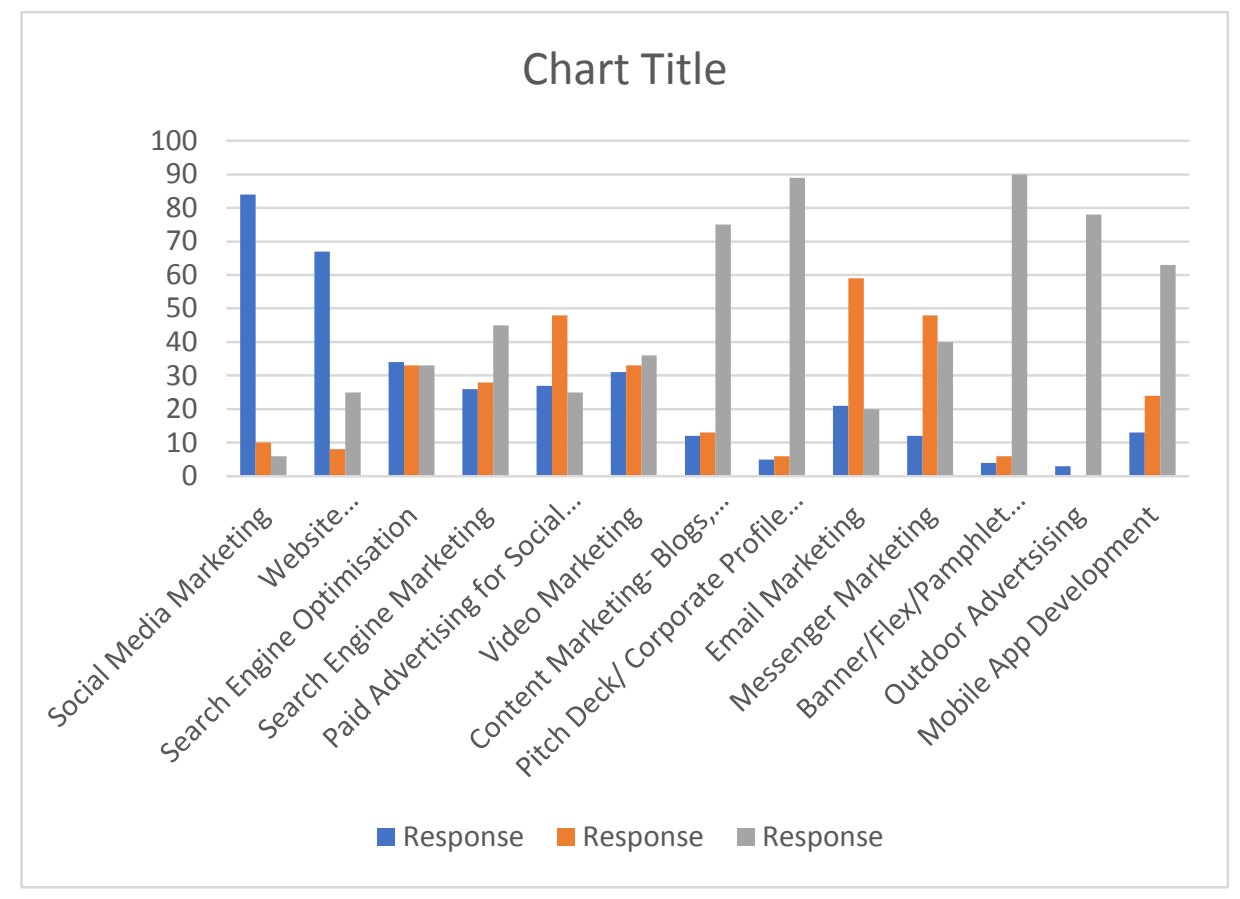

\section{ANALYSIS \& INTERPRETATION}

The above table shows the data gathered $\&$ analysed from the responses given to questionnaire that was sent across to 60 digital marketing agencies \& freelance digital marketers based in Pune. There were 46 respondents to the questionnaire. Through the questionnaire, we asked the respondents to fill out the preference of their clientele towards certain services that were provided by them in order to understand the trends of digital marketing, especially in this pandemic period.

Out of the services provided by the digital companies, the analysis is done on the services which are most preferred, moderately preferred and not preferred by customers during pandemic period.

- $84 \%$ of the respondents classified Social Media Marketing as a highly preferred service by their clientele, $10 \%$ of agencies responded to it being moderately preferred \& the remaining $6 \%$ of the population regarded it to be a service that is not preferred by their clientele in the recent times.

- $67 \%$ of the respondents classified Website Designing/Development or Revamping services as a highly preferred service by their clientele, $8 \%$ of agencies responded to it being moderately preferred \& the remaining $25 \%$ of the population regarded it to be a service that is not preferred by their clientele in the recent times.

- $34 \%$ of the respondents classified Search Engine Optimisation (SEO) as a highly preferred service by their clientele, $33 \%$ of agencies responded to it being moderately preferred \& the remaining $33 \%$ of the population regarded it to be a service that is not preferred by their clientele in the recent times.

- $26 \%$ of the agencies classified Search Engine Marketing as a highly preferred service by their clientele, $28 \%$ of agencies responded to it being moderately preferred \& the remaining $45 \%$ of the population regarded it to be a service that is not preferred by their clientele in the recent times.

- $27 \%$ of the agencies classified Paid Advertising for Social Media as a highly preferred service by their clientele, $48 \%$ of agencies responded to it being moderately preferred \& the remaining $25 \%$ of the population regarded it to be a service that is not preferred by their clientele in the recent times.

- $31 \%$ of the agencies classified Video Marketing as a highly preferred service by their clientele, $33 \%$ of agencies responded to it being moderately preferred \& the remaining $36 \%$ of the population regarded it to be a service that is not preferred by their clientele in the recent times.

- $12 \%$ of the agencies classified Content Marketing (that entails newsletters, blogs, articles etc.) as a highly preferred service by their clientele, $13 \%$ of agencies responded to it being moderately preferred $\&$ the remaining $75 \%$ of the population regarded it to be a service that is not preferred by their clientele in the recent times.

- $5 \%$ of the agencies classified Pitch Deck/Corporate Profile Designing as a highly preferred service by their clientele, $6 \%$ of agencies responded to it being moderately preferred \& the remaining $89 \%$ of the population regarded it to be a service that is not preferred by their clientele in the recent times 
- $21 \%$ of the agencies classified Email Marketing as a highly preferred service by their clientele, $59 \%$ of agencies responded to it being moderately preferred \& the remaining $20 \%$ of the population regarded it to be a service that is not preferred by their clientele in the recent times

- $12 \%$ of the agencies classified Messenger Marketing as a highly preferred service by their clientele, $48 \%$ of agencies responded to it being moderately preferred \& the remaining $40 \%$ of the population regarded it to be a service that is not preferred by their clientele in the recent times

- $4 \%$ of the agencies classified Designing of Marketing Collateral (Like banner, flexes, pamphlets) as a highly preferred service by their clientele, $6 \%$ of agencies responded to it being moderately preferred \& the remaining $90 \%$ of the population regarded it to be a service that is not preferred by their clientele in the recent times.

- $3 \%$ of the agencies classified Outdoor Advertising as a highly preferred service by their clientele, $\&$ the remaining $97 \%$ of the population regarded it to be a service that is not preferred by their clientele in the recent times

- $13 \%$ of the agencies classified Mobile Application Development as a highly preferred service by their clientele, $24 \%$ of agencies responded to it being moderately preferred \& the remaining $63 \%$ of the population regarded it to be a service that is not preferred by their clientele in the recent times

\section{HYPOTHESIS TESTING}

Using percentage analysis as a statistical tool \& by the analysis of the gathered information, it is crystal clear that Social Media Marketing is a service that is highly preferred by businesses. 84\% of the responding agencies \& digital marketers classified Social Media Marketing to be a service that is highly preferred by their clientele.

Thus, H0, i.e "Social Media Marketing is not among the highly preferred digital marketing services by businesses.", is hereby rejected. The alternative hypothesis H1, i.e Social Media Marketing is among the highly preferred digital marketing services by businesses." Is hereby accepted on the basis of this study.

\section{SUGESSTIONS}

From the gathered information \& the analysis the researcher puts forth the following suggestions \& recommendations:

The businesses, in the wake of the current pandemic situation, should have greater indulgence in the digital marketing of their products \& services.

The digital marketing agencies should pitch their services in alignment to the preference of their clientele.

\section{BIBLIOGRAPHY}

I. Books

"Digital Marketing for Dummies" by Russ Henneberry, Ryan Deiss; Published on : 27 December 2016

II. Journals \& Magazines

1. International Journal of Management, IT \& Engineering Vol. 8 Issue 10, October 2018

2. International Journal of Trend in Scientific Research and Development (IJTSRD) Conference Issue | March 2019

III. Websites

1. https://www.seosandwitch.com/digital-marketing-history-india/

2. https://www.prismglobalmarketing.com/blog/how-covid-19-pandemic-impacted-digital-marketing

3. https://www.businessinsider.in/advertising/brands/news/8-out-of-10-indian-marketers-say-digitalmarketing-spends-at-their-company-increased-due-to-covid-19-criteo/articleshow/80784117.cms

4. https://yourstory.com/2020/12/effects-covid-19-digital-marketing/amp

5. https://www.exchange4media.com/marketing-news/criteo-launches-report-covid-19-impact-on-marketingsurvey-india-111052.html

6. https://www.score.org/blog/covid-19-impact-digital-marketing

7. https://adamasuniversity.ac.in/digital-marketing-in-india-is-at-the-cros-road-impact-of-covid-19/

8. https://www.republicworld.com/business-news/india-business/digital-advertising-to-grow-20-percent-by2021-to-reach-rs-23673-cr-by-2022-dentsu-e4mreport.html\#: :text=According\%20to\%20Digital\%20Advertising\%20in, 15\%2C782\%20crore\%20in\%2020 20.\&text $=$ In $\% 20$ India $\% 2 \mathrm{C} \% 20$ the $\% 20$ digital $\% 20$ medium, a $\% 20$ market $\% 20$ size $\% 20$ of $\% 20$ Rs.

9. https://www.google.com/podcasts?feed =aHROcHM6Ly9hbmNob3IuZmOvcy80MzA4OTc1NC9wb2RjYXNOL $3 J z c w==$

10. https://www.nsim.in/blog/future-growth-of-digital-marketing-in-india-2021/ 